\title{
Improved antibody detection by the use of range expansion and longer filter wavelength in a low ionic strength-protamine sulphate Auto- Analyzer system
}

\author{
D. M. DOWNIE AND D. VOAK
}

From the Regional Transfusion and Immuno-Haematology Centre, Long Road, Cambridge

SYNOPSIS Range expansion, achieved by insertion of a variable resistance between the colorimeter and the recorder together with the use of $550 \mathrm{~nm}$ colorimeter filters, has resulted in markedly improved sensitivity for antibody detection, and improved sample identification, in a low ionic strength-protamine sulphate (LISPS) system. Range expansion also permits a lower concentration of red cells to be used, thus economizing on fully typed cells. Glycerol stored frozen cells were found to be only slightly less sensitive than fresh cells in this system.

An automated antibody screening system should detect all antibodies of clinical significance with a sensitivity at least equal to and preferably better than the manual method it replaces. The bromelinmethyl cellulose (BMC) system described by Marsh et al (1968) has the disadvantage of not detecting weak antibodies to the enzyme degradable antigens MNS and Fya, and in our hands did not detect weak anti$K$. Our attention was drawn to the low ionic strength-polybrene/protamine sulphate system described by Lalezari $(1967 ; 1968)$.

In common with Dawes and Goldsmith (1975), we found that polybrene caused the aggregated cells to adhere to the glass coils, owing to the high degree of surface absorption of polybrene to glass, as noted by Greenwalt and Steane (1973). This resulted in cell baseline fluctuations, excessive 'carry-over', and poor sample identification. Reduction in the polybrene concentration to overcome these problems resulted in a loss of sensitivity. These difficulties were not experienced when protamine sulphate (Lalezari, 1967; Judd, 1971) was used, and this became the reagent of choice. Experiments revealed that the LISPS system enhanced the reaction of MNS and $\mathrm{Fy}^{\mathrm{a}}$ antibodies. Anti-K gave reactions equivalent to manual antiglobulin tests, but the system was slightly less sensitive than the BMC system in detecting weak anti-D, thus confirming the findings of Perrault and Högman (1971).

Received for publication 1 April 1976
In developing an automated screening system, it is found that working conditions represent a compromise between sensitivity, as shown by changes in optical density between the baseline and top of the peak, and sample identification. Alterations to the manifold or the chemistry did not produce the sought-after improvement in peak height and sample identification. Therefore the suitability of a range expander (Owen, 1970; Annan and Fisher, 1971) for increasing peak height and sample identification in an inverse colorimetric system such as this was investigated. During the course of the experiments it was decided to examine the effect of filter wavelength, in combination with range expansion, on peak height.

Marsh et al (1968) have drawn attention to the need for a regular supply of fully typed fresh cells for antibody screening. Habibi et al (1973) and Perrault and Högman (1971) overcame this problem by utilizing a selected panel of donors, but the provision of sufficient fully typed fresh cells for antibody screening is often difficult. Marsh et al (1968) and Moore (1969) found that glycerol frozen cells failed to form satisfactory rouleaux in the BMC system, although Kolberg and Nordhagen (1975) have reported satisfactory results with frozen cells in this system. Judd (1971) reported that cells frozen in glycerol or liquid nitrogen were satisfactory in the LISPS system. Therefore a study has been carried out comparing fresh cells with cells frozen in glycerol by the method of Mollison (1972). 


\section{Material and methods}

The LISPS manifold is basically similar to that described by Lalezari (1968). A two-channel machine was assembled around Technicon AA1 modules. Two range expander units were constructed as described by Annan and Fisher (1971).

\section{REAGENTS}

Protamine sulphate (Salmine), Fisons Ltd, batch 04 used at a concentration of $0.1 \%$ in $0.9 \%$ saline. Acid dextrose, pH 3.20, 5.0\% dextrose BP in distilled water containing $2.0 \mathrm{ml}$ of $1.0 \mathrm{M}$ citric acid/litre. Resuspending solution $0.2 \mathrm{M}$ trisodium citrate $\mathrm{pH}$ $8 \cdot 20$. Wash solution $0.3 \mathrm{M}$ trisodium citrate. Triton X-100 (Koch-Light Ltd) $0.5 \%$ in distilled water. Tween 20 (Koch-Light Ltd) $10.0 \%$ in distilled water added to resuspending and wash solutions to a final concentration of $0.02 \%$.

TEST CELLS

Packed cells were stored at $-20^{\circ} \mathrm{C}$ in $3.0 \mathrm{M}$ glycerol and recovered for use by overnight dialysis against phosphate buffered saline $\mathrm{pH} 6 \cdot 80$. They were washed four times and suspended in the same buffer. The strength of the test cells was adjusted according to the colorimeter filter wavelength in use, that is, $14.0 \%$ for use with $550 \mathrm{~nm}$ filters and $6.0 \%$ for 440 nm filters respectively.

Fresh cells were obtained from acid-citrate dextrose blood donations less than 7 days old, washed four times in buffered saline $\mathrm{pH} 6 \cdot 80$, and suspended in the same buffered solution.

\section{TEST SERA}

An anti-D reagent with an albumin titre of 64 (21.9 $\mu \mathrm{g}$ anti-D/ml), a 'papain only' anti-D (approx. $0.01 \mu \mathrm{g}$ anti-D $/ \mathrm{ml}$ ), and anti-K with an antiglobulin titre of 4 , and an anti-Fya with an antiglobulin titre of 8 were serially diluted in antibody free serum from a group $\mathrm{AB}$ donor.

\section{PROCEDURE}

Three sample cups containing the same antibody free group AB serum were placed between each dilution. The anti-D sera were tested $\times R_{2} r$ cells and the anti-K x Kk cells, and the anti-Fya $\times F y(a+b+)$ cells. The same cell was used in both channels and comparative measurements were made with $440 \mathrm{~nm}$ filters in one channel and $550 \mathrm{~nm}$ filters in the second channel. The concentration of the test cell suspension was adjusted to keep the cell baseline in the range $0.70-0.95$ optical density (OD) units. The dilutions were then resampled with the colorimeter $100 \% \mathrm{~T}$ control set at maximum, and with a No. 1 aperture on the reference photocell to give maximum range expansion. The cell baseline was adjusted to $1 \cdot 0-2 \cdot 0 \stackrel{0}{*}$ OD units by means of the range expander.

The cell suspensions were then diluted to half their original concentrations and the dilutions weres? resampled after the cell baseline was adjusted too 0.70-0.95 OD units using the range expander.

\section{SAMPLING RATE}

Sixty samples/hour with a 2:1 sample:wash ratio. The manifold was at ambient temperature, but the resuspending solution was cooled in melting-ice. before introduction into the manifold.

Peak height was measured as change in optical $\stackrel{\omega}{\omega}$ density $(\triangle \mathrm{OD})$ from the cell baseline.

\section{Results}

Figure 1a shows the results obtained with $440 \mathrm{~nm}_{\bullet}$

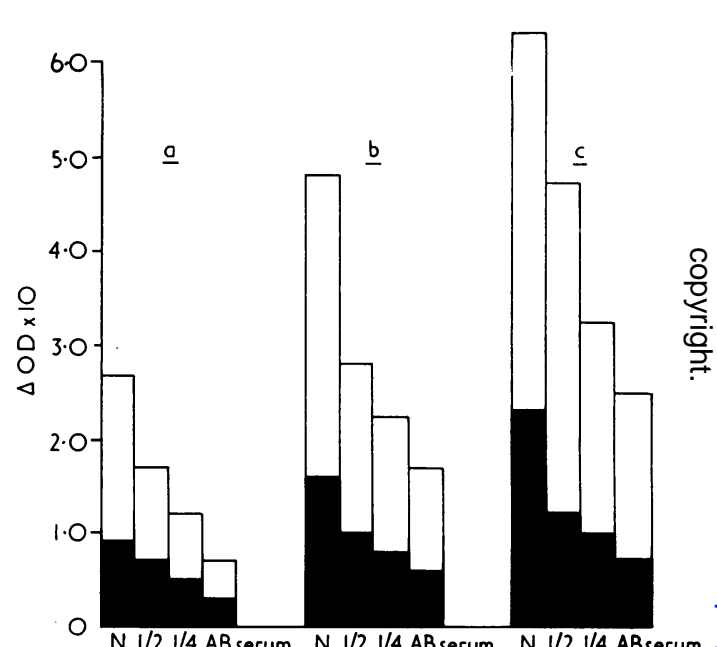

Fig 1 Range expansion and sensitivity of anti-K detection: $\square 550 \mathrm{~nm}$ filters; $\square 440 \mathrm{~nm}$ filters. (a) no range expansion, $550 \mathrm{~nm}$ and $440 \mathrm{~nm}$ filters, $14.0 \%$ and $6.0 \%$ cells respectively; (b) maximum range expansion, 550 and $440 \mathrm{~nm}$ filters, $14.0 \%$ and $6.0 \%$ cells respectively; (c) maximum range expansion, $550 \mathrm{~nm}$ and $440 \mathrm{~nm}$ filters, $7.0 \%$ and $3.0 \%$ cells respectively.

and $550 \mathrm{~nm}$ filters used under their optimum conditions, but without range expansion. In order to maintain the cell baseline within the limits of $0 \cdot 70-\mathrm{\omega}$ 0.95 OD units the cell strengths were adjusted to $14.0 \%$ with the $550 \mathrm{~nm}$ filters and to $6.0 \%$ with the $440 \mathrm{~nm}$ filters. The peak heights obtained with the $550 \mathrm{~nm}$ filters and $14.0 \%$ cells were about one and $\mathrm{a}^{-}$ half times higher than those obtained with $440 \mathrm{~nm}-{ }_{0}^{\circ}$ filters and $6.0 \%$ cells. Figure $\mathrm{lb}$ shows the results 
obtained with maximum range expansion using the same cell concentrations as above. Operation of the range expander brought the cell baseline to between 1.0 and 2.0 OD units. The range expander increased peak height by an average of $80 \%$ with $550 \mathrm{~nm}$ filters and of $60 \%$ with $440 \mathrm{~nm}$ filters. Figure 1c shows the effect of maximum range expansion when the cell strengths were decreased from $14.0 \%$ to $7.0 \%$ and from $6.0 \%$ to $3.0 \%$.

Reduction in the cell concentration allowed an increase in the amount of range expansion obtained because the variable resistance of the range expander needed to be turned to maximum resistance to bring the cell baseline to $1 \cdot 0-2 \cdot 0$ OD units. In practice, any further reduction in the cell concentration to increase range expansion does not give any improvement with either set of filters. The use of cell concentrations weaker than $7 \%$ with $550 \mathrm{~nm}$ filters, or $6 \%$ with 440 $\mathrm{nm}$ filters, does not reliably improve the sensitivity for antibody detection. Also it has the disadvantage of increasing baseline variations beyond useful limits.

The use of a No. 1 reference photocell aperture and turning the ' $100 \% \mathrm{~T}$ ' colorimeter control to maximum allowed a useful increase in range expansion, giving a $20 \%$ increase in antibody sensitivity for the anti-D, anti-Kell, anti-Fy ${ }^{a}$ sera tested.

With $550 \mathrm{~nm}$ filters, $7.0 \%$ cells, and maximum range expansion the increase in peak height was on average $170 \%$ greater than that obtained with $14.0 \%$ cells and no range expansion. With $440 \mathrm{~nm}$ filters and $3.0 \%$ cells the increase in peak height was on average $100 \%$ greater than that obtained with $6.0 \%$ cells and no range expansion.

The AB serum negative control in each set of tests indicates the change in optical density between the cell baseline and a serum sample, which provides the sample identification.

Figure 2 shows the antibody profiles obtained with an anti-K with and without maximum range expansion, and using both $550 \mathrm{~nm}$ and $440 \mathrm{~nm}$ filters at their respective optimum cell concentrations. The best results were obtained by using the $550 \mathrm{~nm}$ filters and full range expansion.

Similar results were obtained with the other antibodies tested. The conditions optimum for anti-K were also found to be optimum for anti-D and antiFya Range expansion also increased the peak height of the neutral AB results, but this had the advantage of providing better sample identification.

\section{COMPARISON OF FRESH AND GLYCEROL}

\section{FROZEN CELLS}

Experiments with anti-D, anti-K, and anti-Fya antibodies under parallel conditions with stored frozen cells and fresh cells of the same genotypes revealed that the sensitivity of antibody detection

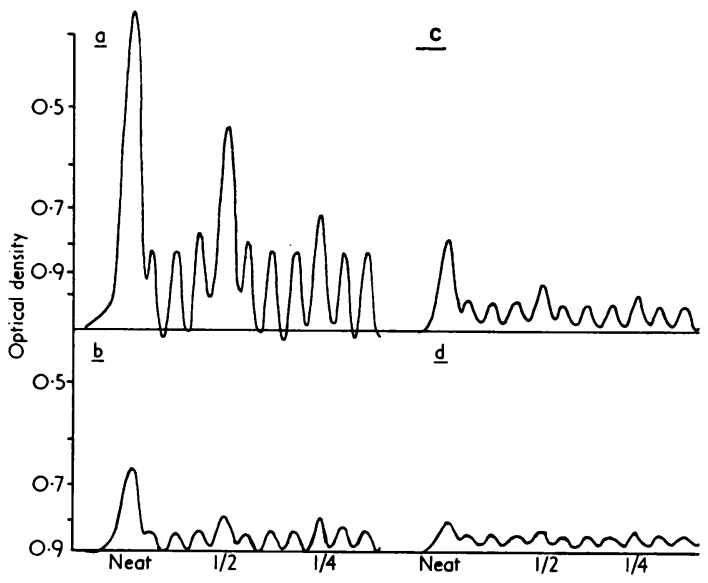

Fig 2 Examples of chart profiles obtained with anti-K: (a) maximum range expansion, $550 \mathrm{~nm}$ filters, $7.0 \%$ cells; (b) no range expansion, $550 \mathrm{~nm}$ filters, $14.0 \%$ cells; (c) maximum range expansion, $440 \mathrm{~nm}$ filters, $6.0 \%$ cells; $(d)$ no range expansion, $440 \mathrm{~nm}$ filters, $6.0 \%$ cells.

with frozen cells was only slightly below that of fresh cells. Peak heights were on average about $10 \%$ lower with frozen cells.

\section{Discussion}

The three anti-sera used throughout this study were a 'papain only' anti-D, a weak anti-K, and a weak anti-Fya. They were selected as the test sera because they are the most difficult type of antibodies to detect. Our experience has shown that a system which will detect these antibodies will give satisfactory results with most other clinically significant antibodies with the possible exception of certain anti-Lewis antibodies. It is important to select 'weak' antibodies, which presumably like 'papain only' anti-D have low association constants (Casey et al, 1972) when investigating optimum conditions for antibody detection. The use of dilutions of more avid antibodies is not as satisfactory since they are too easily detected.

The principle of using a resistance in the circuit between the colorimeter and recorder of an AutoAnalyzer to increase peak height has been discussed by Owen (1970). Annan and Fisher (1971) have described a variable range expander unit easily connected to an AutoAnalyzer system.

We have investigated optimum filter wavelength and test cell concentration in combination with maximum range expansion in a LISPS antibody screening system. Initial experiments showed that 
without range expansion there was no difference in sensitivity between $440 \mathrm{~nm}$ and $550 \mathrm{~nm}$ filters, which is in accordance with the findings of Perrault and Högman (1971). However, baseline 'noise' levels were much greater with $550 \mathrm{~nm}$ than with 440 $\mathrm{nm}$ filters, owing to the smaller change in optical density produced by the lower test cell concentration that must be used with the latter. Range expansion magnified the 'noise' as well as the signal, as noted by Owen (1970). It is important to keep baseline 'noise' levels to the minimum as large fluctuations are manifested as 'false positive' peaks and give poor sample identification. Baseline 'noise' levels are easily brought to an acceptable level by the addition of Tween 20 to the wash and resuspending solutions as recommended by Gunson et al (1972). This did not cause any significant reduction in sensitivity for antibody detection, and did not cause the aggregated cells to adhere to the glass coils as Dawes and Goldsmith (1975) observed with polybrene.

Habibi et al (1973), Judd (1971), Lalezari (1968), and Perrault and Högman (1971) used $440 \mathrm{~nm}$ colorimeter filters with test cell concentrations between 6.5 and $10.0 \%$. Dawes and Goldsmith (1975) described the use of $550 \mathrm{~nm}$ filters with a test cell concentration of $15.0 \%$. In this study we have demonstrated that with maximum range expansion the optimum cell concentrations are $7.0 \%$ for 550 $\mathrm{nm}$ filters and $6.0 \%$ for $\mathbf{4 4 0} \mathrm{nm}$ filters. Reduction in the test cell concentration from $14.0 \%$ to $7.0 \%$ allowed a larger degree of range expansion, giving increased antibody sensitivity and improved sample identification while allowing a $50 \%$ saving in the quantity of fully typed cells needed to run the machine. Reduction of the test cell concentration below $7.0 \%$ resulted in undesirable increased baseline fluctuations. Range expansion also increased peak height of the neutral AB serum results, but this was beneficial, resulting in improved sample identification without the need for antibody containing 'marker' samples.

In common with Marsh et al (1968), we found that glycerol frozen cells show greatly reduced sensitivity in the BMC system for anti-K, anti-Fya, anti-Jk ${ }^{\mathbf{a}}$, and 'papain only' anti-D. Our attempts to obtain improved sensitivity in the BMC system by increasing the concentration of methyl cellulose, as suggested by Kolberg and Nordhagen (1975), did not give satisfactory results. Therefore we cannot recommend the use of frozen cells in a BMC system. However, $\stackrel{\overrightarrow{5}}{\overrightarrow{0}}$ glycerol frozen cells reacted satisfactorily in the LISPS system, confirming the findings of Judd $\overrightarrow{\vec{F}}$ (1971). This has the advantage that a whole donation? may be stored and aliquots recovered for use in the absence of a regular supply of fresh fully typed $\frac{\bar{c}}{\bar{c}}$ cells.

We wish to thank Dr J. Darnborough for his supportis and encouragement throughout these studies.

\section{References}

Annan, W. and Fisher, G. W. (1971). A range expander unit for AutoAnalyzer recorders. J. med. Lab. Technol., 28, 308-C 309.

Casey, F. M., Dodd, B. E., and Lincoln, P. J. (1972). A study of the characteristics of certain $R \mathbf{h}$ antibodies preferen- $-\overrightarrow{-}$ tially detectable by enzyme technique. Vox Sang. (Basel), 23, 493-507.

Dawes, B. J. and Goldsmith, K. L. G. (1975). Automated redo cell antibody detection: an improved method. Vox Sang. (Basel), 29, 248-252.

Greenwalt, T. J. and Steane, E. A. (1973). Quantitative $Z$ haemagglutination VI. Relationship of sialic acid content of red cells and aggregation by polybrene, protamine and poly-1-lysine. Brit. J. Haemat., 25, 227.

Gunson, H. H., Phillips, P. K., and Stratton, F. (1972). The effect of surfactant in the AutoAnalyzer. Vox Sang. (Basel), 22, 183-187.

Habibi, B., Gerbal, A., and Salmon, C. (1973). A papaํ. bromelin-polybrene four-channel AutoAnalyzer system for blood group antibody screening. Vox Sang. (Basel), 289-297.

Judd, J. (1971). Automated antibody screening using $\frac{\partial}{\bar{\partial}}$ protamine sulphate. Technicon Symposium 'Automation in Analytical Chemistry' London, Sept. 15th.

Kolberg, J. and Nordhagen, R. (1975). An evaluation of some factors affecting the detection of blood group antibodies by $\overrightarrow{\vec{\sigma}}$ automated methods. Transfusion, 15, 334-339.

Lalezari, P. (1967). A new method for the detection of red cell antibodies. Technicon Symposium 'Automation in Analytical Chemistry' New York, Oct. 2, 1966.

Lalezari, P. (1968). A new method for detection of red blood cell antibodies. Transfusion, 8, 372-380.

Marsh, W. L., Nichols, M., and Jenkins, W. J. (1968). Automated detection of blood group antibodies. J. med. Lab. Technol., 25, 335-342.

Mollison, P. L. (1972). Blood Transfusion in Clinical Medicine, 5th edition, p. 688. Blackwell, Oxford.

Moore, B. P. L. (1969). Automation in the blood transfusion 을 laboratory: 1 . Antibody detection and quantitation in the Technicon AutoAnalyzer. J. Canad. med. Ass. J., 100, 381- $\frac{7}{0}$ 387.

Owen, J. A. (1970). Range expansion in AutoAnalyzer $N$ recorders. Clin. chim. Acta, 29, 89-91.

Perrault, R. and Högman, C. (1971). Automated red cell anti- N body analysis, a parallel studv. 1 . Detection and quantita- N tion. Vox Sang. (Basel), 20, 340-355. 